Research Paper

\title{
Assessing a crop water stress index derived from aerial thermal imaging and infrared thermometry in super-high density olive orchards
}

\author{
Gregorio Egea ${ }^{\mathrm{a}, *}$, Carmen M. Padilla-Díaz ${ }^{\mathrm{b}}$, Jorge Martinez-Guanter ${ }^{\mathrm{a}}$, José E. Fernández ${ }^{\mathrm{b}}$, \\ Manuel Pérez-Ruiz ${ }^{\mathrm{a}}$ \\ a Area of Agroforestry Engineering, Aeroespace Engineering and Fluids Mechanic Department, School of Agricultural Engineering, Universidad de Sevilla, \\ Ctra. Utrera km.1, 41013 Seville, Spain \\ ${ }^{\mathrm{b}}$ Irrigation and Crop Ecophysiology Group, Instituto de Recursos Naturales y Agrobiología de Sevilla (IRNAS, CSIC), Avenida Reina Mercedes 10, 41012, \\ Seville, Spain
}

\section{A R T I C L E I N F O}

\section{Article history:}

Received 22 September 2016

Received in revised form 20 February 2017

Accepted 28 March 2017

Available online 2 April 2017

\section{Keywords:}

CWSI

Olea europaea

Precision irrigation

Spatial variability

Transpiration

\begin{abstract}
A B S T R A C T
Characterization of the spatio-temporal variability of tree water status is a prerequisite to conducting precise irrigation management in fruit tree orchards. This study assessed the suitability of a crop water stress index (CWSI) derived from high-resolution aerial thermal imagery for estimating tree water status variability in super high density (SHD) olive orchards. The experiment was conducted at a commercial SHD olive orchard near Seville (southwestern Spain), with drip irrigated trees under three irrigation treatments (four plots per treatment in a randomized block design): a full irrigation treatment to replace the crop water needs (ETc) and two regulated deficit irrigation treatments to replace ca. 45\% of ETc. Meteorological variables, soil moisture content, leaf water potential, stem water potential and leaf gas exchange measurements were performed along the irrigation season. Infrared temperature sensors (IRTs) installed approximately $1 \mathrm{~m}$ above the canopies were used to derive the required Non-Water-Stressed Baselines (NWSBs) for CWSI calculation. NWSBs were not common during the growing season, although the seasonal effect could be partly explained with solar angle variations. A thermal camera installed on a mini Remotely Piloted Aircraft System(RPAS) allowed for the recording of high-resolution thermal images on 5 representative dates during the irrigation season. The CWSI values derived from aerial thermal imagery were sensitive to the imposed variations in tree water status within the SHD olive orchard. Among the recorded variables, maximum stomatal conductance showed the tightest correlation with CWSI. We concluded that high-resolution thermal imagery captured from a mini RPAS is a suitable tool for defining tree water status variability within SHD olive orchards.
\end{abstract}

(c) 2017 Elsevier B.V. All rights reserved.

\section{Introduction}

Hedgerow olive orchards with high plant densities $\left(>1500\right.$ trees ha $^{-1}$ ), or super high density (SHD) olive orchards, have expanded dramatically since the early 1990 s. Over 100,000 ha are currently under this management system, half of them in Spain (Rius and Lacarte, 2010). Most SHD olive orchards are under irrigation, requiring $c a .5000 \mathrm{~m}^{3} \mathrm{ha}^{-1}$ to replace maximum crop evapotranspiration in semi-arid areas such as SW Spain (Fernández et al., 2013). This explains the increasing interest in developing precision irrigation techniques to increase water productivity (Cuevas et al., 2013; Egea et al., 2016; Fernández et al., 2013;

\footnotetext{
* Corresponding author.

E-mail address: gegea@us.es (G. Egea).
}

Gómez Del Campo and García, 2013; Padilla-Díaz et al., 2016). The spatial variability in crop water needs caused by soil heterogeneity and differences in canopy cover may be an important limitation for efficient irrigation when water is applied uniformly across the orchard (Couvreur et al., 2016). Characterization of the spatial variability of crop water needs is therefore a prerequisite to apply precise irrigation management within SHD olive orchards. It will allow to supply different irrigation amounts to zones within the orchard with different water requirements. Mapping the spatio-temporal variability of tree water needs with conventional methods such as the pressure chamber (Scholander et al., 1965) is time and labor consuming (Jiménez-Bello et al., 2011). In addition, the reliability of the information provided by the pressure chamber decreases when the species shows an isohydric behavior, characterized by a strong stomatal regulation that avoids marked decreases in leaf water potentials under conditions of low soil 
water and high evaporative demand (Fernández, 2014). There are other conventional although reliable indicators of water stress, such as the stomatal conductance but, once again, measurements must be made manually (Jones, 2007).

Remote sensing techniques offer a promising alternative to traditional tree water status measurements, as they provide a snapshot of the whole orchard over a reduced period of time. The advent of Remote Piloted Aerial Systems (RPAS) has offered an opportunity to develop remote sensing-based methodologies for precision irrigation more affordably than the costly airborne campaigns with manned aircrafts and with higher spatial and temporal resolutions than those normally offered by satellites.

Various sources of remotely sensed imagery, with differences in spectral, spatial, radioactive and temporal characteristics, are known to be suitable for different purposes of vegetation mapping (Xie et al., 2008). Among these sources, thermal imagery of vegetation is becoming popular for water stress detection and for irrigation management purposes (Bellvert et al., 2016b; Berni et al., 2009). This is due to the existing relationship between crop transpiration rate and canopy temperature through a cooling effect that the former exerts on vegetation temperature (Maes and Steppe, 2012). Since the refinement of the technique for measuring crop surface temperature with infrared thermometers in the 1960s (Fuchs and Tanner, 1966), thermal remote sensing has been extensively used to diagnose plant water stress in multiple crop species (Hatfield et al., 1985; Nielsen and Anderson, 1989; Sepulcre-Cantó et al., 2006; Testi et al., 2008). Variations in crop temperature are due to water stress, but are also affected by various meteorological and morphological factors (Maes and Steppe, 2012). Therefore crop temperature must be normalized before being used as water stress indicator. In the early 1980s, Idso et al. (1981) and Jackson et al. (1981) developed the concept of CWSI, a normalized index that overcomes the influence that other environmental variables play on the relationship between crop temperature and water stress. Since then, CWSI has been successfully used in a variety of crops, in which temperature readings were often made with hand-held infrared thermometers (Alderfasi and Nielsen, 2001; Hatfield et al., 1985). Currently, the combined used of modern high-resolution thermal infrared cameras and RPAS offer the possibility to map spatial variability in tree water status from thermal imaging and temperature-derived indicators (Bellvert et al., 2016a). As reviewed in Maes and Steppe (2012), CWSI can be determined by at least three different methodologies. Among them, the empirical CWSI has attained much more popularity and become more successful among scientists and non-scientists mainly due to the limited data requirements and straightforward calculation as compared to the analytical and direct methodologies (Agam et al., 2013; Maes and Steppe, 2012). Idso et al. (1981) calculated the empirical CWSI as follows:

$C W S I=\frac{\left(T_{c}-T_{a}\right)-\left(T_{c}-T_{a}\right)_{L L}}{\left(T_{c}-T_{a}\right)_{U L}-\left(T_{c}-T_{a}\right)_{L L}}$

where $T_{\mathrm{c}}-T_{\mathrm{a}}$ denotes the measured canopy-air temperature difference; $\left(T_{\mathrm{C}}-T_{\mathrm{a}}\right)_{\mathrm{LL}}$ is the lower limit of $\left(T_{\mathrm{C}}-T_{\mathrm{a}}\right)$ for a given vapor pressure deficit (VPD) which is equivalent to a canopy transpiring at the potential rate; and $\left(T_{\mathrm{C}}-T_{\mathrm{a}}\right)_{\mathrm{UL}}$ is the maximum $\left(T_{\mathrm{c}}-T_{\mathrm{a}}\right)$, which corresponds to a non-transpiring canopy. $\left(T_{\mathrm{C}}-T_{\mathrm{a}}\right)_{\mathrm{LL}}$ is a linear function of VPD (non-water-stressed baseline, NWSB) that, once empirically obtained, $\left(T_{\mathrm{C}}-T_{\mathrm{a}}\right)_{\mathrm{LL}}$ is calculated by solving the baseline equation for the actual VPD.

To our knowledge, there are two reports in the literature that provide empirical NWSBs for olive trees (Bellvert et al., 2016a; Berni et al., 2009). However, both equations are reasonably different as denoted by the very small (expressed as absolute value) slope $\left(-0.35^{\circ} \mathrm{C} \mathrm{kPa}^{-1}\right)$ obtained by Berni et al. (2009) as compared to that $\left(-2.05^{\circ} \mathrm{C} \mathrm{kPa}^{-1}\right)$ reported in Bellvert et al. (2016a). These dif-
Table 1

Weather variables measured during 2015 at a nearby standard weather station belonging to the Agroclimatic Information Network of the Junta of Andalusia. $P$ (mm): rainfall; $T_{\mathrm{a}}\left({ }^{\circ} \mathrm{C}\right)$ : air temperature; $\mathrm{RH}(\%)$ : relative humidity; $u\left(\mathrm{~m} \mathrm{~s}^{-1}\right)$ : wind speed; $R_{\mathrm{S}}\left(\mathrm{MJ} \mathrm{m}^{-2} \mathrm{~d}^{-1}\right)$ : solar radiation; $\mathrm{ET}_{0}\left(\mathrm{~mm} \mathrm{~d}^{-1}\right)$ is the calculated FAO-Penman Monteith reference crop evapotranspiration. The suffixes av, $\mathrm{mx}$ and $\mathrm{mn}$ indicate the average, maximum and minimum, respectively.

\begin{tabular}{lllllllllll}
\hline Month & $P$ & $T_{\mathrm{av}}$ & $T_{\mathrm{mx}}$ & $T_{\mathrm{mn}}$ & $\mathrm{RH}_{\mathrm{av}}$ & $\mathrm{RH}_{\mathrm{mx}}$ & $\mathrm{RH}_{\mathrm{mn}}$ & $u$ & $R_{\mathrm{s}}$ & $\mathrm{ET}_{0}$ \\
\hline Jan & 42.2 & 8.8 & 16.0 & 2.8 & 82 & 99 & 50 & 2.3 & 10.3 & 1.5 \\
Feb & 6.8 & 9.4 & 15.8 & 3.4 & 75 & 95 & 45 & 2.5 & 12.5 & 2.1 \\
Mar & 42.0 & 12.8 & 21.1 & 5.2 & 73 & 95 & 40 & 1.7 & 18.2 & 3.1 \\
Apr & 26.8 & 16.4 & 24.0 & 9.3 & 71 & 97 & 38 & 1.6 & 21.5 & 4.0 \\
May & 0.4 & 21.6 & 31.4 & 11.9 & 50 & 86 & 20 & 1.6 & 27.6 & 6.2 \\
Jun & 2.2 & 24.0 & 32.8 & 14.8 & 47 & 77 & 23 & 2.4 & 28.5 & 7.3 \\
Jul & 0.0 & 28.1 & 37.4 & 18.6 & 42 & 66 & 17 & 2.6 & 29.9 & 8.9 \\
Aug & 1.6 & 26.1 & 34.3 & 18.7 & 50 & 73 & 26 & 2.6 & 23.6 & 7.0 \\
Sep & 28.6 & 21.7 & 29.4 & 14.8 & 59 & 83 & 31 & 2.6 & 20.4 & 5.2 \\
Oct & 73.4 & 18.7 & 25.0 & 13.7 & 74 & 92 & 45 & 1.9 & 12.6 & 2.9 \\
Nov & 33.0 & 13.7 & 22.1 & 7.0 & 68 & 91 & 39 & 1.7 & 12.5 & 2.1 \\
Dec & 25.2 & 12.0 & 20.3 & 5.5 & 70 & 90 & 42 & 1.3 & 9.1 & 1.6 \\
Year & 282.2 & 17.8 & 25.8 & 10.5 & 63 & 87 & 35 & 2.1 & 18.9 & 4.3 \\
\hline
\end{tabular}

ferences in the sensitivity of $T_{\mathrm{C}}-T_{\mathrm{a}}$ to VPD in olive are so important that more research is needed to reduce the degree of uncertainty in the appropriate NWSB to be used in SHD olive orchards. Moreover, these studies provided a single NWSB obtained with measurements collected at a certain daytime (e.g. 12:30 GMT in Berni et al. (2009)), but a comprehensive study on how NWSB varies both along the day and the season is lacking in olive trees.

To reduce the lack of information mentioned above on the use of CWSI and NWSB in olive, we design this study according to the following objectives: (i) to determine the NWSB for olive in a commercial SHD olive orchard as well as its diurnal and seasonal (throughout the irrigation season) time courses, (ii) to compute CWSI throughout the irrigation season in trees under three irrigation treatments from the obtained NWSB and high resolution aerial thermal imagery taken from a mini RPAS, and (iii) to assess the suitability of the derived CWSI values to estimate the variation of tree water status within SHD olive orchards.

\section{Materials and methods}

\subsection{Experimental site}

The experiment was conducted in 2015 at a commercial SHD olive orchard near Seville, in southwestern Spain (37.248979, -5.796538 ). Nine year-old olive trees (Olea europaea L., cv. Arbequina) were planted with $4 \mathrm{~m} \times 1.5 \mathrm{~m}$ tree spacing $\left(1667\right.$ trees ha $^{-1}$ ). The drip irrigation system consisted of one drip line per tree row and three $2 \mathrm{~L} \mathrm{~h}^{-1}$ pressure compensating drippers ( $0.5 \mathrm{~m}$ apart) per tree. One flow meter per irrigation treatment recorded the amount of water applied during each irrigation event. An irrigation controller (Agronic 2000, Sistemes Electrònics PROGRÉS, S.A., Lleida, Spain) was used for irrigation scheduling. Trees were fertilized to cover the crop needs and no weeds were allowed to grow in the inter-row spacing over the spring-summer seasons.

The climate of the study area is Mediterranean, with rainfall occurring normally from late September to May. The average annual value of potential reference evapotranspiration $\left(\mathrm{ET}_{0}\right)$ and precipitation calculated for the 2002-2014 period from data recorded by a standard weather station belonging to the Andalusian government and located near the orchard, were $1528 \mathrm{~mm}$ and $540 \mathrm{~mm}$, respectively. Table 1 shows the weather data (monthly averages) recorded over the experimental year. The orchard soil has a sandy loam top layer $(0.0-0.4 \mathrm{~m})$ and a sandy clay layer (0.4-1.0 $\mathrm{m}$ ) underneath. The electrical conductivity of the saturated soil-paste (ECe), $\mathrm{pH}$ and organic matter content determined in the $0.0-0.4 \mathrm{~m}$ soil layer were $2.5 \mathrm{dS} \mathrm{m}^{-1}, 6.34$ and $0.28 \%$, respectively. 


\subsection{Irrigation treatments}

Three irrigation treatments were established in the orchard, as described in Padilla-Díaz et al. (2016): a full irrigation treatment (FI) in which the trees were irrigated daily for the whole irrigation season to supply $100 \%$ of the irrigation needs (IN), and two regulated deficit irrigation treatments (45RDI) for which the total water supplied during the season was aimed to replace $45 \%$ of IN. One of the 45RDI treatments was scheduled on the basis of the crop coefficient method $\left(45 \mathrm{RDI}_{\mathrm{CC}}\right)$, whereas the other $45 \mathrm{RDI}$ treatment was scheduled from leaf turgor related measurements $\left(45 \mathrm{RDI}_{\mathrm{TP}}\right)$ made with ZIM probes (Zimmermann et al., 2008). The 45RDI trees were irrigated with enough water to replace IN in three periods of the year when olive is most sensitive to water stress (Fernández, 2014): from the last stages of floral development to full bloom (period 1, mid-April), at 6-10 weeks after full bloom (period 2, June) and some 3 weeks prior to ripening (period 3, from late August to midSeptember). For the rest of the year just one or two irrigation events per week are applied. The crop coefficient method was applied for scheduling irrigation in both the FI and $45 \mathrm{RDI}_{\mathrm{CC}}$ treatments, with crop coefficients adjusted for the orchard conditions by Fernández et al. (2013). For the 45RDI ${ }_{\mathrm{TP}}$ treatment irrigation was scheduled from the outputs of the ZIM probes, which are related to the leaf turgor pressure. We used the approach described by Padilla-Díaz et al. (2016). Basically, the shape of the daily curves provided by the ZIM probes and the 3-day weather forecast were used to adjust irrigation in the three periods mentioned above, such that the irrigation amounts were close or equal to IN in those periods. In between the periods and after period 3, all treatments were irrigated with the crop coefficient approach and according to the 45RDI strategy described by Fernández (2014). We used four $16 \mathrm{~m}$ x $12 \mathrm{~m}$ plots per treatment, in a randomized block design. Each plot contained 32 trees, of which measurements were made on the central 8 trees to avoid border effects.

\subsection{Thermal imagery acquisition}

A thermal infrared (TIR) camera (Tau 2 324, FLIR Systems, Inc., Oregon, USA) was mounted on a multirotor RPAS (Remote Piloted Aerial System) model Phantom 2 (SZ DJI Technology Co., Ltd., Shenzhen, China). The RPAS is equipped with a GNSS receptor, has flight autonomy of $25 \mathrm{~min}$ and a remote control range of $1000 \mathrm{~m}$ in open spaces. The TIR camera was installed to aim vertically downward (nadir view) at the bottom of the RPAS. The camera spectral range is 7.5 $-13.5 \mu \mathrm{m}$ with a resolution of $324 \times 256$ pixels, a focal length of $9 \mathrm{~mm}$, and a field of view of $49^{\circ}(\mathrm{H}) \times 39^{\circ}(\mathrm{V})$. The RPAS was flown across the experimental orchard on five clear sky days, at $20 \mathrm{~m}$ above the ground level and at solar noon, delivering thermal images with a ground spatial resolution of $5 \mathrm{~cm}$. The thermal images were stored on board in a raw format with 14-bit radiometric resolution. At the time of each flight, surface temperature measurements of ground targets were used for indirect calibration of the thermal imagery (Bellvert et al., 2014; Dupin et al., 2011). In particular, a cold (wet cotton sheet) and hot references ( $40 \mathrm{~cm} \times 50 \mathrm{~cm}$ black plastic panels) located in the center of each experimental plot along with four monitored trees with infrared thermometers (IRTS) (Section 2.4) were used as ground targets. The cold and hot references were measured with a hand-held infrared thermometer model FLUKE 62 Max (FLUKE, Washington, DC, USA).

\subsection{Measurements at ground level}

Volumetric soil water content $(\theta)$ was measured in all plots $(\mathrm{n}=4)$ with a PR2-type Profile Probe (Delta-T Devices Ltd, Cambridge, UK). In each location, measurements were made at 0.1 , $0.2,0.3,0.4,0.6$ and $1.0 \mathrm{~m}$ depth, once every $7-10$ days throughout the irrigation season. The $\theta$ measurements were always performed after an irrigation event, between 10:00 and 12:00 Greenwich Mean Time (GMT), i.e. close to solar noon at the longitude of our experimental site. The probe was calibrated in situ by Fernández et al. (2011). The $\theta$ values were used to calculate changes in the relative extractable water (REW) for all treatments, as described elsewhere (Fernández et al., 2013). The midday stem water potential $\left(\Psi_{\mathrm{st}}\right)$ was measured with a Scholander-type pressure chamber (PMS Instrument Company, Albany, Oregon, USA) on the same days that the RPAS was flown. One leaf per tree, from the inner part of the canopy, was wrapped in aluminum foil ca. $2 \mathrm{~h}$ before sampling, in two representative trees per $\operatorname{plot}(\mathrm{n}=8)$. Measurements of $\Psi_{\text {st }}$ were made at 11:30-12:30 GMT when minimum daily values are usually recorded in olive. Stomatal conductance $\left(g_{\mathrm{sm}}\right)$ was measured on the same days and on the same trees where $\Psi_{\text {st }}$ was measured, but between 09:00-10:00 GMT, the time of maximum daily stomatal conductance in this species (Fernández et al., 1997). A Licor LI-6400 portable photosynthesis system (Li-cor, Lincoln Nebraska, USA) with a $2 \mathrm{~cm} \times 3 \mathrm{~cm}$ standard chamber was used to measure $g_{\mathrm{sm}}$ and leaf transpiration rate $\left(E_{\mathrm{m}}\right)$ in sunny leaves of current-year shoots from the outer part of the canopy facing SE and in ambient light $\left(\approx 1500 \mu \mathrm{mol} \mathrm{m}^{-2} \mathrm{~s}^{-1}\right)$ and $\mathrm{CO}_{2}\left(370-400 \mu \mathrm{mol} \mathrm{mol}^{-1}\right)$ conditions.

Four Infrared Remote Temperature Sensors (IRTs) (model IR120, Campbell Scientific Ltd., Shepshed, UK) were mounted over two representative trees of one out of four plots in FI and $45 \mathrm{RDI}_{\mathrm{TP}}$ treatments. The sensors had an angular field of view of $20^{\circ}$ (half angle), and the accuracy over the calibrated range was $\pm 0.2^{\circ} \mathrm{C}$. The IRTs were mounted on galvanized steel masts with a horizontal mounting arm (model IR1 $\times 0$, Campbell Scientific Ltd., Shepshed, UK) ending with a white PVC solar shield (model IR-SS, Campbell Scientific Ltd., Shepshed, UK) to protect the sensor. The IRTs were mounted to aim vertically downward (nadir view), targeting the center of the canopy from a distance of approximately $1 \mathrm{~m}$. The dense canopies typical of hedgerow olive orchards allowed the IRTs to view mostly foliage in a circular area of approximately $0.7 \mathrm{~m}$ diameter at the top of the canopy. The IRTs were connected to two dataloggers (model CR1000, Campbell Scientific Ltd., Shepshed, $\mathrm{UK})$, which recorded the canopy temperatures $\left(T_{\mathrm{c}}\right)$ every minute and stored the 15 -min averages. The canopy temperature measurements began on June 16th, 2015 (DOY 167) and continued with a sole interruption of 12 days due to power outage until November 5 th (DOY 275).

Values of $T_{\mathrm{c}}$ measured with the IRTs above the FI trees were used to derive the Non-Water-Stressed Baselines (NWSB) for CWSI calculation. Only clear-sky days were used for NWSB determination. Clear-sky days following a rainfall event were also discarded to avoid errors associated with wet foliage. Air temperature $\left(T_{\mathrm{a}}\right)$ along with VPD data were recorded in the orchard every $30 \mathrm{~min}$ with a Campbell weather station (Campbell Scientific Ltd., Shepshed, UK) at the same time that $T_{\mathrm{c}}$ were used to derive the NWSB of the SHD olive orchard.

\subsection{Image processing and CWSI calculation}

The thermal images taken with the RPAS (Fig. 1) were used to calculate the mean canopy temperature $\left(T_{\mathrm{c}}\right)$ of each experimental plot. Only the central 8 trees of each plot were used to calculate the mean $T_{\mathrm{c}}$ to avoid border effects. An image segmentation algorithm written in R (R Core Team, 2015) was used to extract pure vegetation pixels from the thermal image. At solar noon, the effects of tree shadow are minimized, and the thermal images are composed mainly of canopy, soil and mixed plant-soil pixels. Firstly, vegetation pixels from a bi-modal histogram (i.e. a histogram with two clearly differentiated peaks ascribed to soil and vegetation pixels in the point cloud) (Fig. 2) were selected with the mentioned algo- 

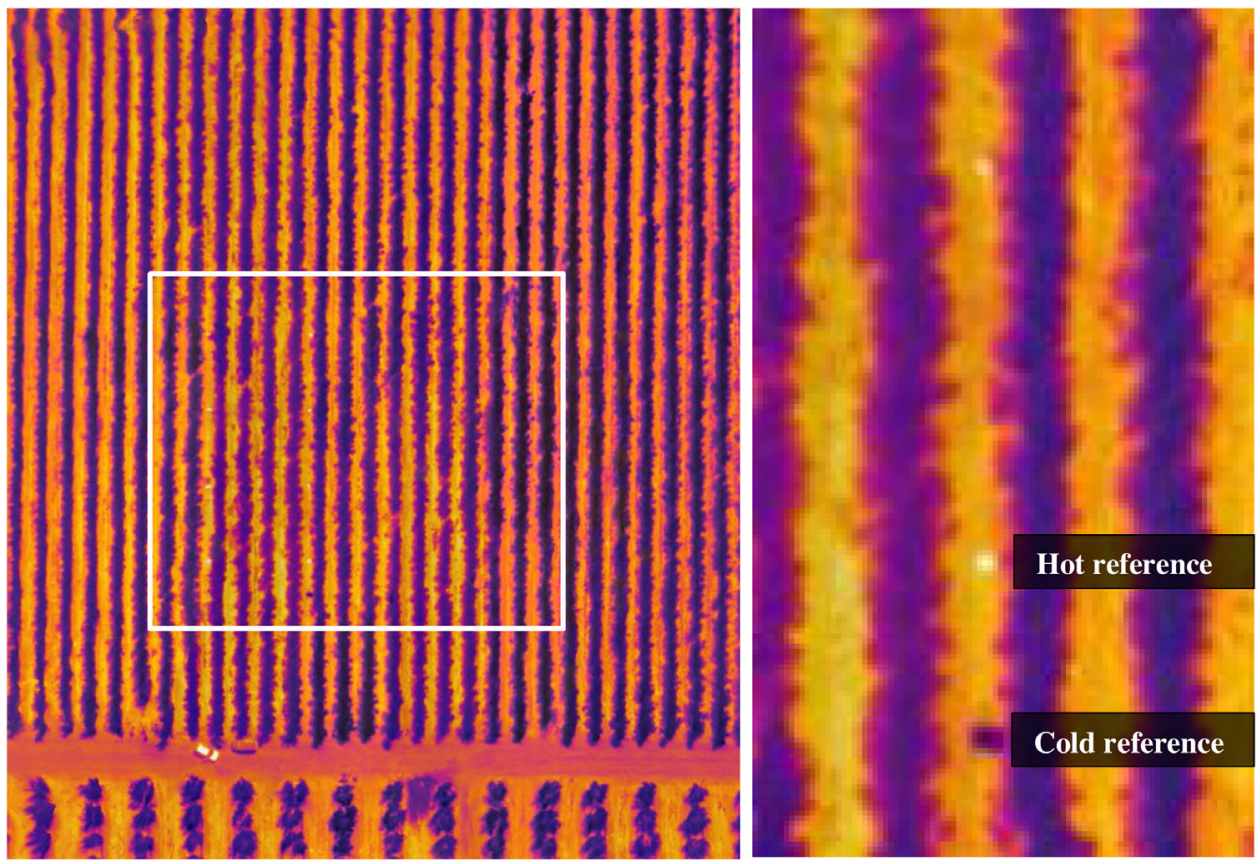

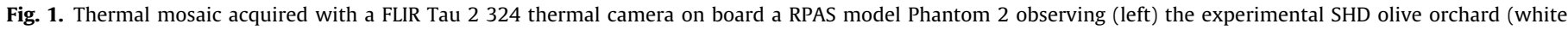
rectangle), and (right) details of the hot and cold reference surfaces.

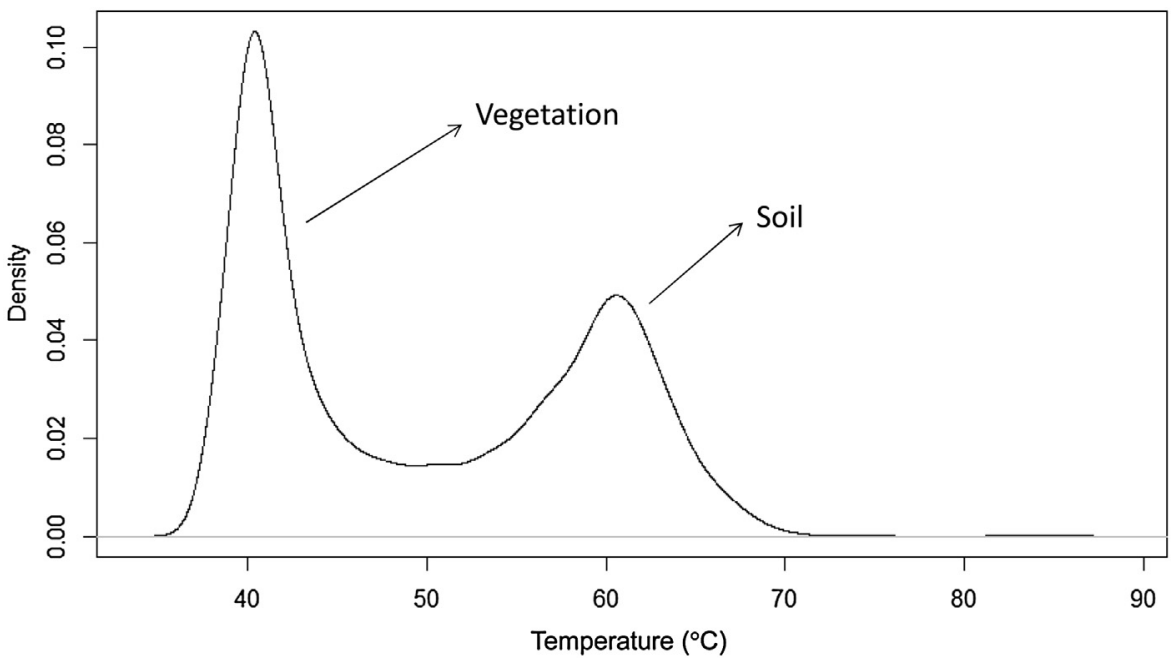

Fig. 2. Example of bi-modal histogram of temperatures obtained from a thermal image of an experimental plot.

rithm. Then, the 'full width at one-eighth maximum (FWEM)' rule was used to distinguish the pixels with high probability of being pure vegetation from pixels that were likely to be mixed vegetation with soil and/or shadow effects. The FWEM rule is similar to the 'full width at half maximum' (FWHM) rule that has been previously used to extract pure vegetation pixels from olive canopies (Rud et al., 2015), but differed in the amplitude of the selected histogram (one-eighth of the maximum in FWEM versus half the maximum in FWHM). FWHM demonstrated a lack of suitability for segmenting thermal images with multiple trees that differ greatly in their $T_{c}$, since vegetation pixels from trees with severe water stress can be erroneously discarded by the FWHM rule (Fig. 3). The selected segment resulting from the FWEM rule was then used to compute the mean $T_{\mathrm{c}}$ for each experimental plot.

Mean $T_{\mathrm{c}}$ was used to calculate the CWSI for each experimental plot using Eq. (1). For each day of flight, $\left(T_{\mathrm{C}}-T_{\mathrm{a}}\right)_{\mathrm{LL}}$ was calculated from the NWSB that was determined with the IRTs, as described in Section 2.4 and with the actual air VPD. The value of $\left(T_{\mathrm{c}}-T_{\mathrm{a}}\right)_{\mathrm{UL}}$ was determined as $T_{\mathrm{a}}+5{ }^{\circ} \mathrm{C}$ based on previous studies conducted in different crop species (Irmak et al., 2000; Möller et al., 2007), including olive trees (Agam et al., 2014, 2013; Ben-Gal et al., 2009; Rud et al., 2015).

\subsection{Statistical analyses}

The relationships between $T_{\mathrm{c}}-T_{\mathrm{a}}$ and VPD (NWSBs) as well as between CWSI and the physiological measurements were analyzed through linear regression analyses. The diurnal time-course of slopes and intercepts of the derived NWSBs was modeled through non-linear regression analysis. In all cases, the coefficient of determination $\left(\mathrm{R}^{2}\right)$ was used to assess the goodness of fit of the associations among variables. Significant differences between slopes and non-zero intercepts of the NWSBs obtained diurnally and seasonally were evaluated with the Comparison of Regression 


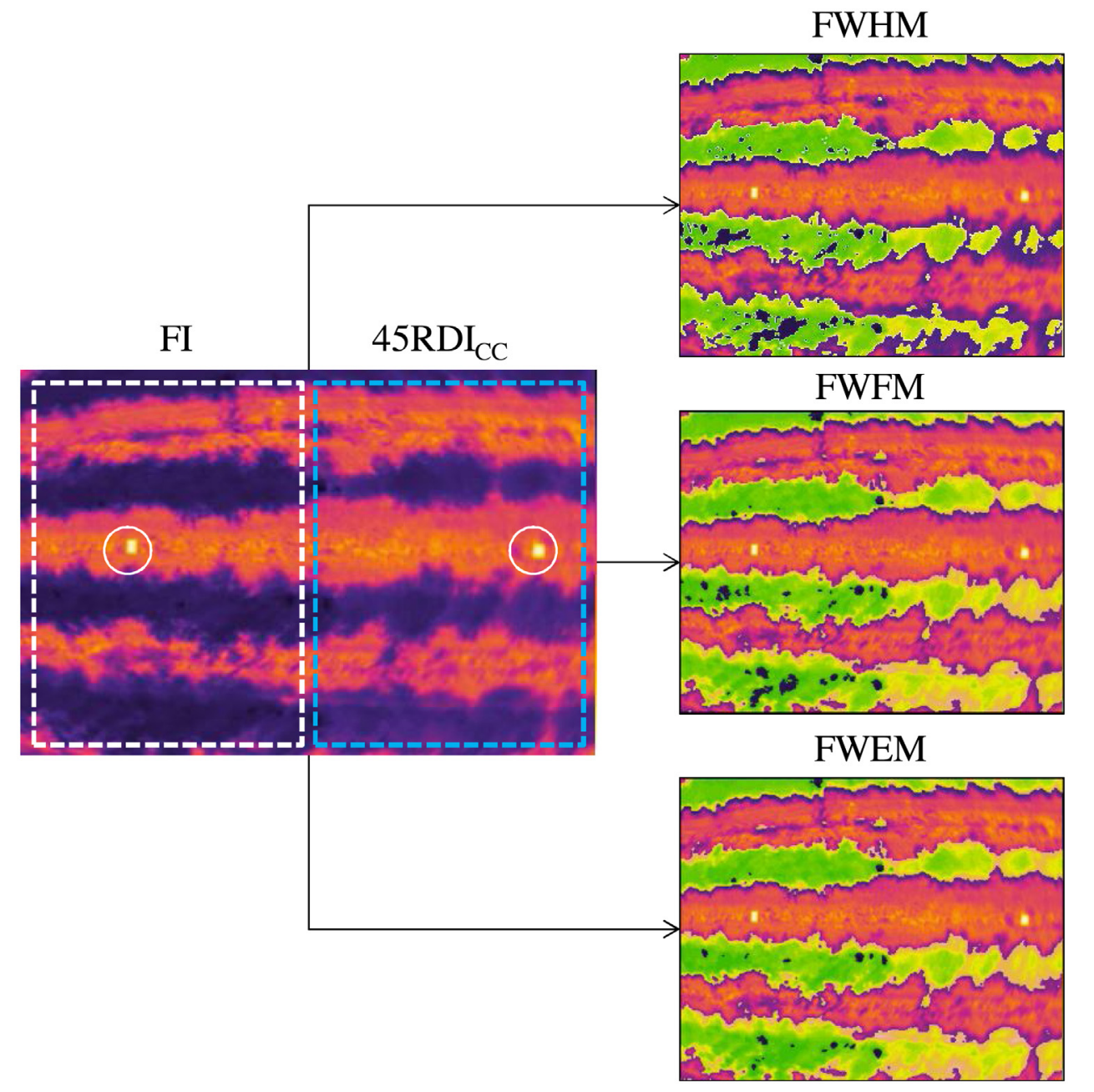

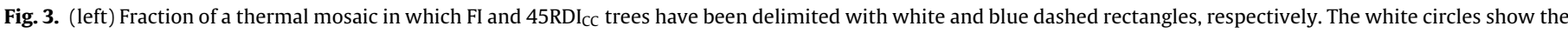

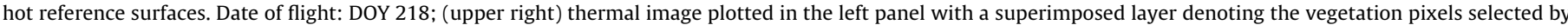

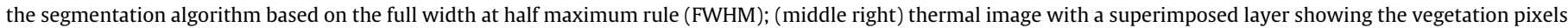

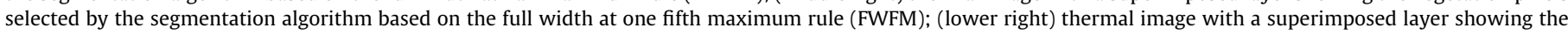

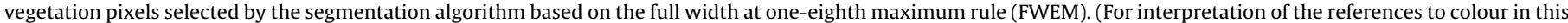
figure legend, the reader is referred to the web version of this article.)

Lines tool included in the statistical package Statgraphics (Statgraphics Centurion XV).

\section{Results}

\subsection{Non-Water-Stressed baselines}

The relationship between hourly $\Delta T\left(T_{\mathrm{c}}-T_{\mathrm{a}}\right)$ and VPD values derived for FI olive trees in clear-sky days throughout the study period, did not yield any significant relationship when all hours and days were pooled together (data not shown). The relationships became significant when $\Delta T$ and VPD were regressed for a given time of the day, as shown in Table 2. The coefficients of determination $\left(R^{2}\right)$ were notably affected by the daytime. The highest $R^{2}$ were observed early in the morning $\left(R^{2}=0.74\right.$ at 8.00 GMT). These values decreased progressively down to 0.28 (14:00 GMT), recovering partially afterwards $\left(R^{2}=0.51\right.$ at $\left.18.00 \mathrm{GMT}\right)$. The intercepts and slopes of the fitted NWSBs also varied throughout the day. The intercepts were higher at midday (2.50 at 12:00 GMT) and lower in the morning and afternoon whereas the slopes showed an increasing trend throughout the day (from $-0.77^{\circ} \mathrm{C} \mathrm{kPa}^{-1}$ at 8.00 GMT to around $-0.3^{\circ} \mathrm{C} \mathrm{kPa}^{-1}$ in the evening).
Table 2

Fitted parameters for the non-water stressed baselines $\left(T_{\mathrm{c}}-T_{\mathrm{a}}=\mathrm{a}+\mathrm{b} \cdot \mathrm{VPD}\right)$. Only clear-sky days from day of year 167-275 were used in the analyses. GMT: Greenwich Mean Time.

\begin{tabular}{llll}
\hline GMT & Intercept ${ }^{\circ} \mathrm{C}$ & Slope $^{\circ} \mathrm{C} \mathrm{kPa}^{-1}$ & $R^{2}$ \\
\hline $08: 00$ & 0.94 & -0.77 & 0.74 \\
$09: 00$ & 0.97 & -0.67 & 0.64 \\
$10: 00$ & 1.44 & -0.61 & 0.67 \\
$11: 00$ & 2.18 & -0.55 & 0.70 \\
$12: 00$ & 2.50 & -0.36 & 0.49 \\
$13: 00$ & 2.43 & -0.30 & 0.32 \\
$14: 00$ & 2.05 & -0.32 & 0.28 \\
$15: 00$ & 1.43 & -0.30 & 0.35 \\
$16: 00$ & 0.83 & -0.30 & 0.41 \\
$17: 00$ & 0.31 & -0.31 & 0.42 \\
$18: 00$ & -0.09 & -0.32 & 0.51 \\
\hline
\end{tabular}

In addition to the diurnal effect on the NWSBs, a marked seasonal effect in the $\Delta T$ vs VPD relationship was also observed (Fig. 4), as the NWSB shifted in August (Period B) and September (Period C), compared to the values derived in June-July (Period A). When $\triangle T$ and VPD of a given time of the day and for a given period were regressed, the level of agreement of the NWSBs increased significantly, and the diurnal effect of $R^{2}$ observed using 

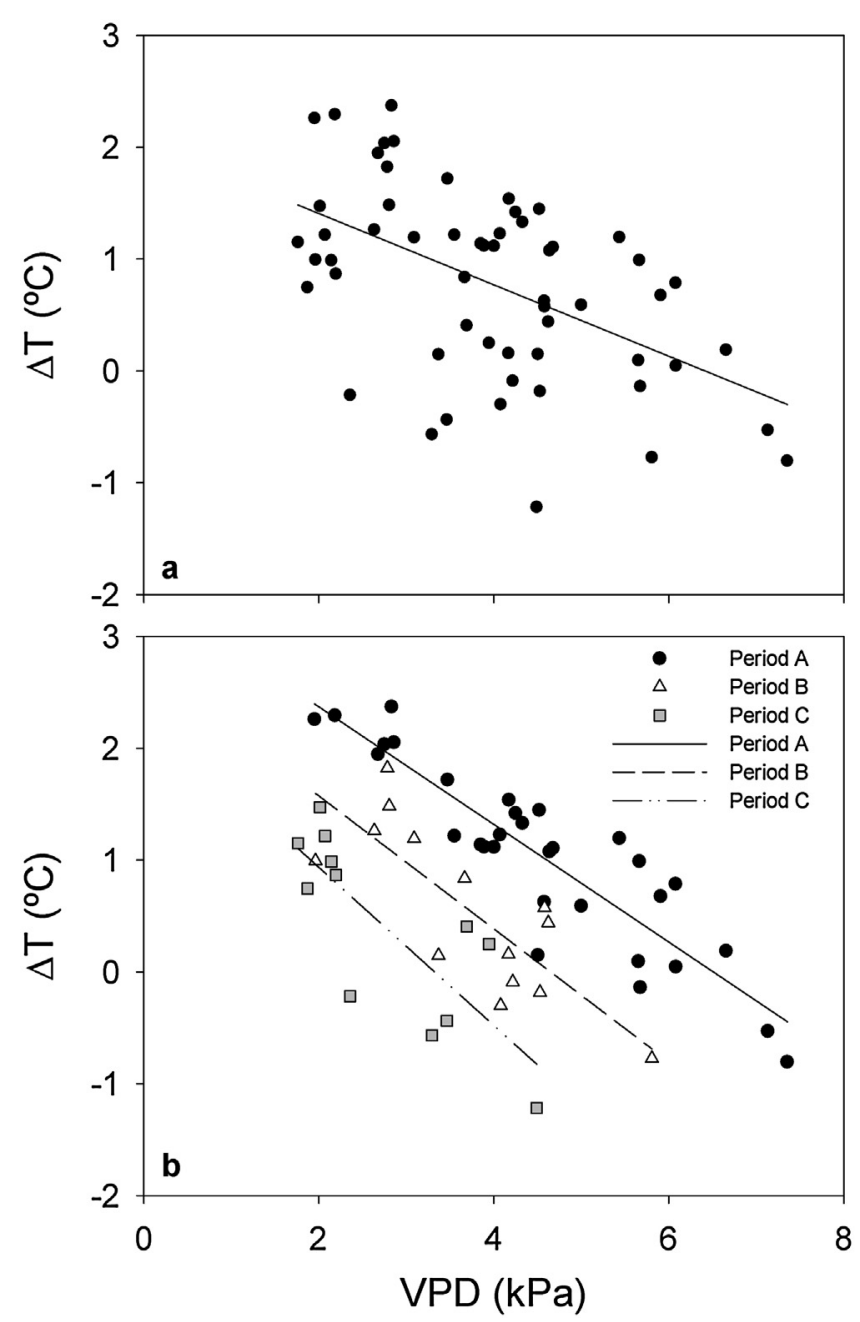

Fig. 4. Example of seasonal effect on the NWSB $(\Delta T=a+b \cdot V P D)$. The upper panel (a) shows the $\triangle T$ vs VPD relationship when data of the period DOY 167-275 are gathered together. The lower panel (b) shows the same relationship when data are split in three periods: A (June-July, DOY 167-212), B (August, DOY 215-243), C(September, DOY 244-273). Only clear-sky days were used in the calculations. In both panels, data for GMT $=14 \mathrm{~h}$ have been used. The straight lines represent the best fit to the data, whose fitted parameters and coefficients of determination are shown in Tables 2 (panel a) and 3 (panel b).

pooled data (Table 2) was not noticed (Table 3). Seasonal variations in the NWSBs were mainly due to significant variations in the NWSB-intercepts, as the NWSB-slopes remained almost invariant throughout the irrigation season (Table 3). As observed for the NWSBs obtained with pooled data (Table 2), the NWSBs derived during the three periods of study (A, B and C) also exhibited a strong diurnal variation (Fig. 5). The diurnal time-course of the NWSBintercepts was successfully modeled with fourth-order polynomial equations during the three periods of study (A, B and C) (Fig. 6), whereas that of the NWSB-slopes was successfully modeled with second-order polynomial equations (Fig. 7). In order to reduce the empiricism and site specificity of these models, the parameters of the NWSBs obtained were regressed against the zenith solar angle (Testi et al., 2008). While the relation between the NWSBslopes and zenith solar angle was not significant (data not shown), the NWSB-intercepts showed a tight relationship with solar angle (Fig. 8). As depicted in Fig. 8a, this relationship showed a marked hysteresis during periods $A$ and $B$ but not in period $C$. When the dataset was split into morning and afternoon data, it was observed that the relationship NWSB-intercept vs solar angle was seasondependent during the morning hours only (period $C$ differed from
Table 3

Fitted parameters for the non-water-stressed baselines $\left(T_{\mathrm{c}}-T_{\mathrm{a}}=\mathrm{a}+\mathrm{b} \cdot \mathrm{VPD}\right)$ determined for three representative periods: A (June-July, day of year-DOY-167-212), B (August, DOY 215-243), C (September, DOY 244-273). Only clear-sky days were used. GMT: Greenwich Mean Time.

\begin{tabular}{|c|c|c|c|c|}
\hline GMT & Period & Intercept $\left({ }^{\circ} \mathrm{C}\right)$ & Slope $\left({ }^{\circ} \mathrm{kPa}^{-1}\right)$ & $R^{2}$ \\
\hline 08:00 & A & $1.02 \mathrm{a}$ & $-0.79 a$ & 0.72 \\
\hline 08:00 & B & $1.15 a$ & $-1.00 a$ & 0.68 \\
\hline 08:00 & $\mathrm{C}$ & $1.32 \mathrm{a}$ & $-1.40 a$ & 0.75 \\
\hline 09:00 & A & $1.28 \mathrm{a}$ & $-0.73 a$ & 0.74 \\
\hline 09:00 & B & $0.97 b$ & $-0.83 a b$ & 0.56 \\
\hline 09:00 & $\mathrm{C}$ & $1.79 b$ & $-1.50 b$ & 0.82 \\
\hline $10: 00$ & A & $1.68 \mathrm{a}$ & $-0.64 a$ & 0.77 \\
\hline $10: 00$ & B & $1.67 b$ & $-0.89 a$ & 0.67 \\
\hline $10: 00$ & $C$ & $1.91 b$ & $-1.02 \mathrm{a}$ & 0.70 \\
\hline $11: 00$ & A & $2.60 \mathrm{a}$ & $-0.62 a$ & 0.82 \\
\hline $11: 00$ & B & $2.06 \mathrm{~b}$ & $-0.58 \mathrm{a}$ & 0.52 \\
\hline $11: 00$ & C & $2.84 \mathrm{~b}$ & $-0.98 a$ & 0.68 \\
\hline $12: 00$ & A & $3.29 a$ & $-0.50 a$ & 0.82 \\
\hline $12: 00$ & B & $2.85 b$ & $-0.54 a$ & 0.71 \\
\hline $12: 00$ & C & $2.86 \mathrm{c}$ & $-0.70 a$ & 0.56 \\
\hline $13: 00$ & A & $3.53 a$ & $-0.47 a$ & 0.82 \\
\hline $13: 00$ & B & $2.68 b$ & $-0.45 a$ & 0.67 \\
\hline $13: 00$ & C & $2.98 c$ & $-0.71 \mathrm{a}$ & 0.66 \\
\hline $14: 00$ & A & $3.42 \mathrm{a}$ & $-0.53 a$ & 0.81 \\
\hline $14: 00$ & B & $2.76 b$ & $-0.59 a$ & 0.65 \\
\hline $14: 00$ & C & $2.35 c$ & $-0.71 \mathrm{a}$ & 0.63 \\
\hline $15: 00$ & A & $2.60 a$ & $-0.48 a$ & 0.82 \\
\hline $15: 00$ & B & $2.09 b$ & $-0.54 a$ & 0.76 \\
\hline $15: 00$ & C & $1.67 \mathrm{c}$ & $-0.62 a$ & 0.60 \\
\hline $16: 00$ & A & $1.55 \mathrm{a}$ & $-0.41 \mathrm{a}$ & 0.80 \\
\hline $16: 00$ & B & $1.40 \mathrm{~b}$ & $-0.49 a b$ & 0.65 \\
\hline $16: 00$ & C & $1.33 c$ & $-0.67 b$ & 0.66 \\
\hline $17: 00$ & A & $1.11 \mathrm{a}$ & $-0.45 a$ & 0.69 \\
\hline $17: 00$ & B & $0.88 b$ & $-0.50 a$ & 0.77 \\
\hline $17: 00$ & C & $0.64 c$ & $-0.68 a$ & 0.79 \\
\hline $18: 00$ & A & $0.56 a$ & $-0.45 a$ & 0.79 \\
\hline $18: 00$ & B & $0.56 a$ & $-0.64 b$ & 0.88 \\
\hline $18: 00$ & C & $0.01 \mathrm{~b}$ & $-0.64 a b$ & 0.90 \\
\hline
\end{tabular}

Different letters within each GMT denote significant differences at $P<0.05$.

A and B) (Fig. 8b), whereas no seasonal effect on NWSB-intercept was observed during the afternoon (Fig. 8c).

\subsection{Crop water stress index derived from IRTs and RPAS}

The canopy temperature measurements obtained with the IRTs and with the thermal camera mounted on the RPAS were used to derive the seasonal dynamics of CWSI in the irrigation treatments (Figs. 9a, b). The CWSI obtained from the IRT readings was markedly influenced by the irrigation regime (Fig. 9a). In FI, CWSI values ranged within the interval -0.17 to 0.15 throughout the irrigation season, with a mean value of 0.00 . During the first water stress period depicted in Fig. 9 (DOY 174-236), the deficit irrigation treatment monitored with the IRTs (45RDI $\mathrm{TP}_{\mathrm{TP}}$ ) exhibited values of CWSI that were much higher than those found in FI trees, up to approximately 0.7 (Fig. 9a). During the last water stress period (DOY 258 onwards), the differences in CWSI between FI and $45 \mathrm{RDI}_{\mathrm{TP}}$ were lower, with values close to 0 and 0.2 , respectively.

The CWSI values determined from aerial thermal imaging in $\mathrm{FI}, 45 \mathrm{RDI}_{\mathrm{TP}}$ and $45 \mathrm{RDI}_{\mathrm{CC}}$ treatments are depicted in Fig. 9b. The FI trees exhibited values of CWSI that ranged from -0.07 to 0.17 , with mean seasonal values of 0.04 . The $45 \mathrm{RDI}_{\mathrm{TP}}$ and $45 \mathrm{RDI}_{\mathrm{CC}}$ treatments showed similar trends, with maximum values close to 0.8 observed during the first water stress period. The differences in CWSI between FI and 45RDI treatments for DOY 239 and 281 were 

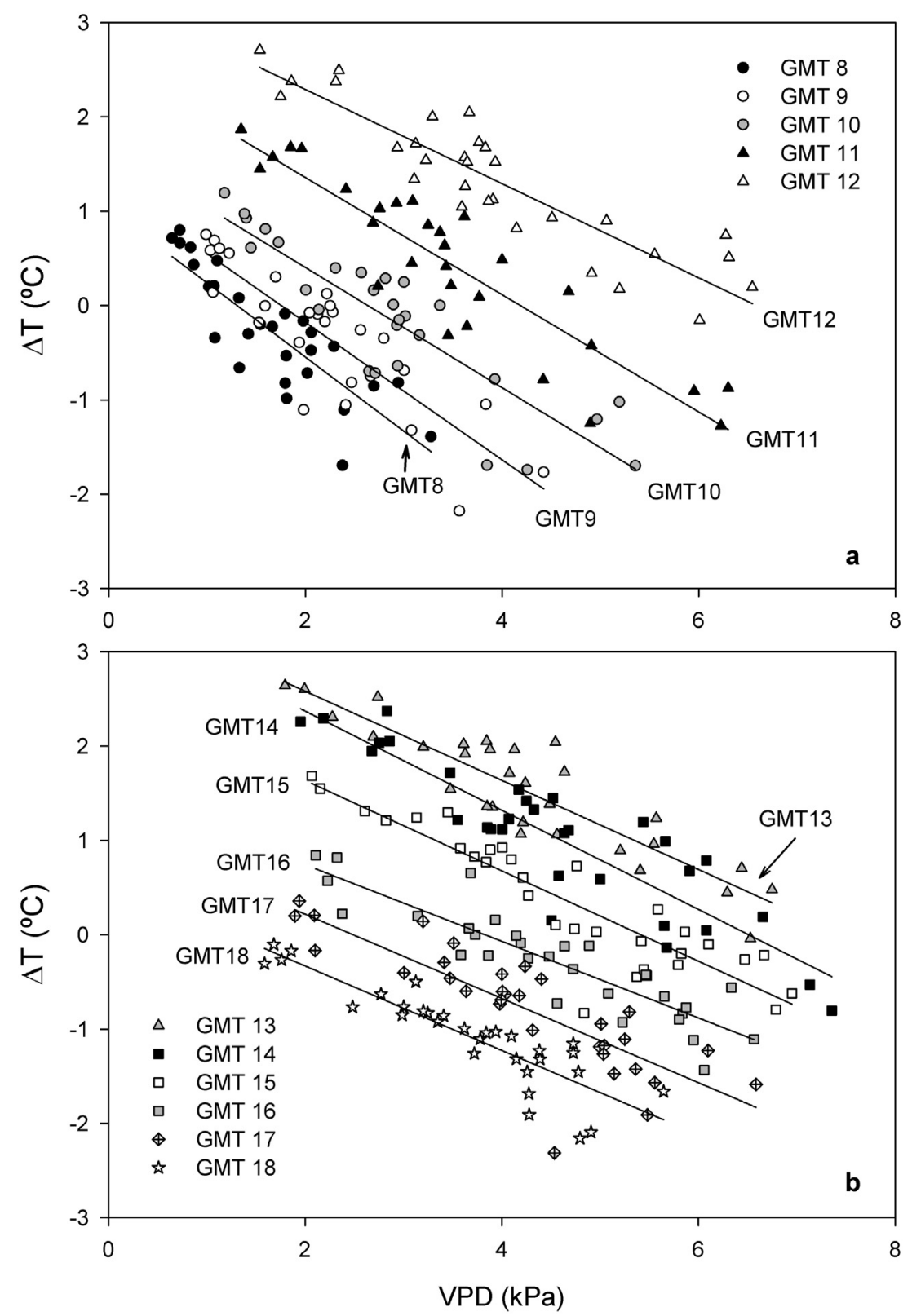

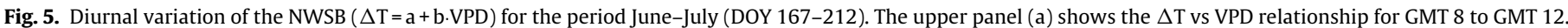

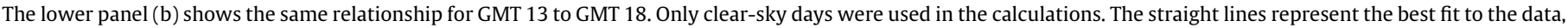
whose fitted parameters and coefficients of determination are shown in Table 3.

much smaller and not statistically significant, with mean values close to $0.3-0.4$ in $45 \mathrm{RDI}_{\mathrm{TP}}$ and $45 \mathrm{RDI}_{\mathrm{CC}}$ and close to 0 in FI. The seasonal trend of CWSI derived from aerial thermal imaging was similar to that of REW (Fig. 9c), which also revealed significant differences between FI and the 45RDI treatments during the first water stress period but not afterwards.

\subsection{Relationship between CWSI and other plant-based water status indicators}

The CWSI values derived from aerial thermal imaging for the five days of flight and the three irrigation treatments were plotted against stem water potential $\left(\Psi_{\text {st }}\right)$, leaf water potential $\left(\Psi_{1}\right)$, stomatal conductance $\left(g_{\mathrm{sm}}\right)$ and leaf transpiration rate $\left(E_{\mathrm{m}}\right)$ (Fig. 10). In all cases, significant $(P<0.01)$ linear regressions were observed. The goodness of fit of the relationship between $\Psi_{\text {st }}$ and $\Psi_{1}$ with CWSI were similar, with coefficients of determination close to 0.7
(Figs. 9a, 9b). The relationship between leaf transpiration rate $\left(E_{\mathrm{m}}\right)$ and CWSI was somewhat weaker than that previously described for $\Psi_{\text {st }}$ and $\Psi_{1}$, with a coefficient of determination of 0.6 (Fig. 10d). Stomatal conductance $\left(g_{\mathrm{sm}}\right)$ was the physiological variable that exhibited the tightest linear relationship with CWSI, with a coefficient of determination of 0.91 (Fig. 10c).

\section{Discussion}

The diurnal variation observed in the non-water-stressed baselines (NWSBs) derived for olive trees (Fig. 5) has already been described in other woody species, such as pistachio (Testi et al., 2008) and grapevine (Bellvert et al., 2014). Both of these studies found that diurnal shifts in the NWSBs were mainly due to variations in the NWSB-intercept, as the slope of the baselines was rather stable. As explained theoretically by Jackson et al. (1981), the intercept of the NWSB is expected to increase with solar radi- 


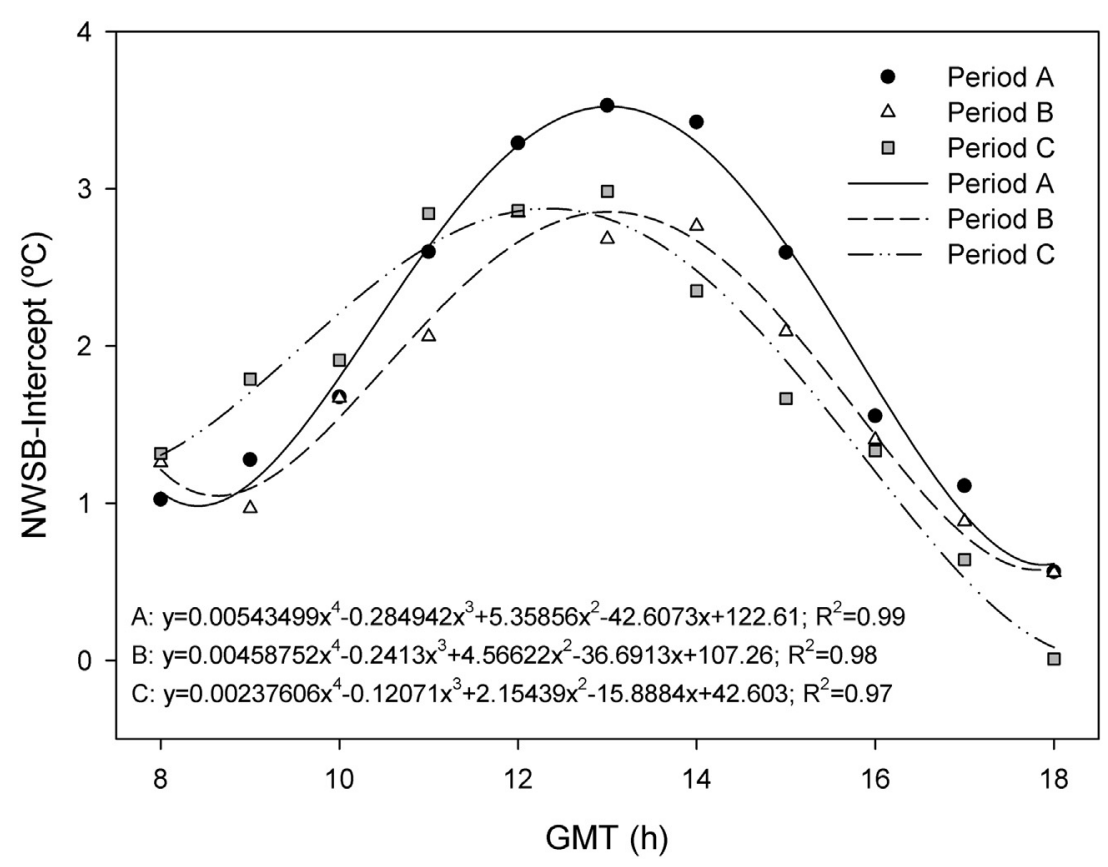

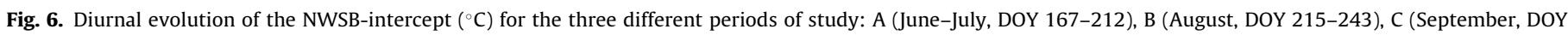
244-273). The lines represent the best-fit to the data.

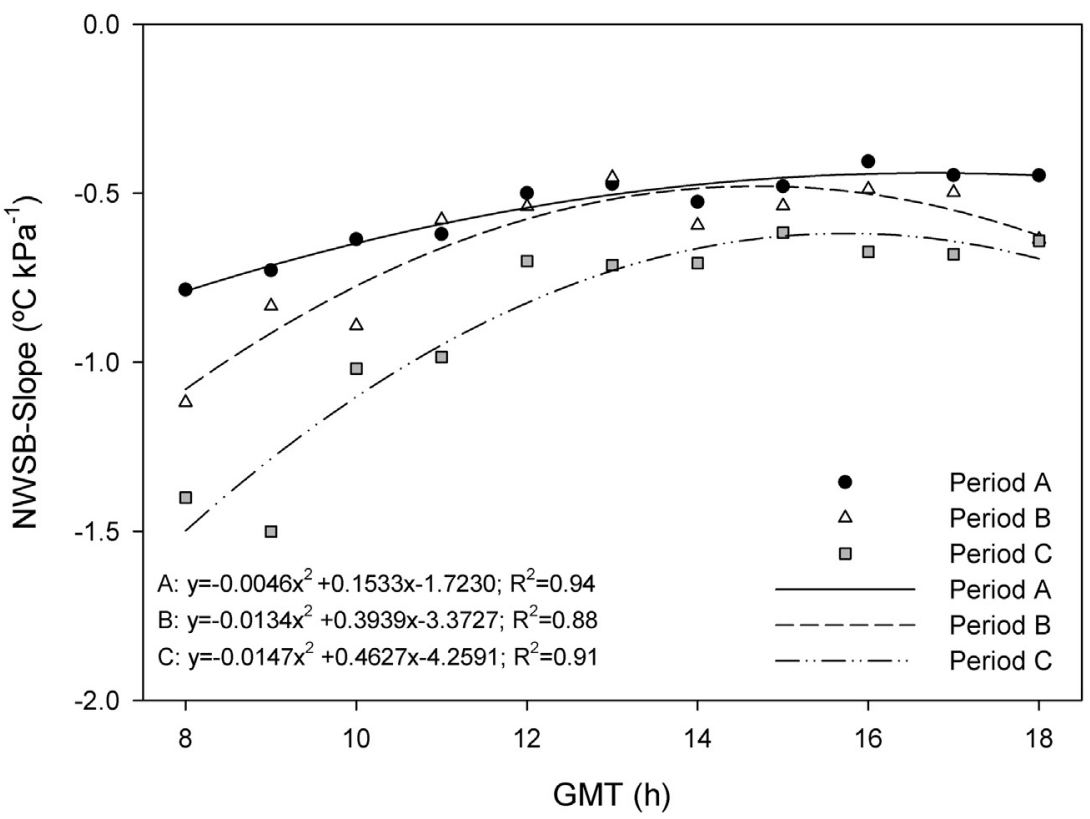

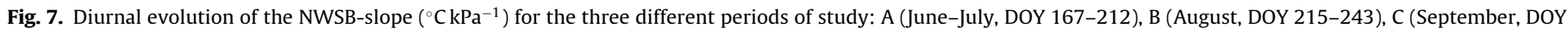
244-273). The lines represent the best-fit to the data.

ation and to decrease with wind speed. In our case study, diurnal variations of the NWSB-intercept due to wind speed are unlikely since the experimental area is not particularly windy (diurnal wind speed was below $2 \mathrm{~m} \mathrm{~s}^{-1}$ most of the days) and the effect of low to moderate wind speed on NWSB has been reported to be negligible (Testi et al., 2008), although it has to be noted that was in a different species with different aerodynamic conductance for sensible heat flux. Therefore, the observed diurnal variation in the NWSB-intercept (Tables 2 and 3) was likely driven by solar radiation, as evidenced by the tight relationship found with zenith solar angle (Fig. 8). As compared to previous findings in which NWSBintercept and solar angle were linearly related (Testi et al., 2008), in our olive trees the relationship showed a marked hysteresis during periods A and B (Fig. 8a). This behaviour indicates that, for similar radiation and VPD levels, the cooling effect of transpiration in the summer (periods A and B) is higher during the morning hours. This can be due to the fact that, in olive, stomata opening is greater in the morning than in the afternoon (Fernández et al., 1997). Therefore, transpiration and its cooling effect is also greater in morning than in afternoon hours. Unlike what has been observed in previous studies on woody crops (Bellvert et al., 2014; Testi et al., 2008), the diurnal evolution of the NWSB-slope in olives was stable only from 12:00 GMT onwards, whereas an increasing trend that was more 

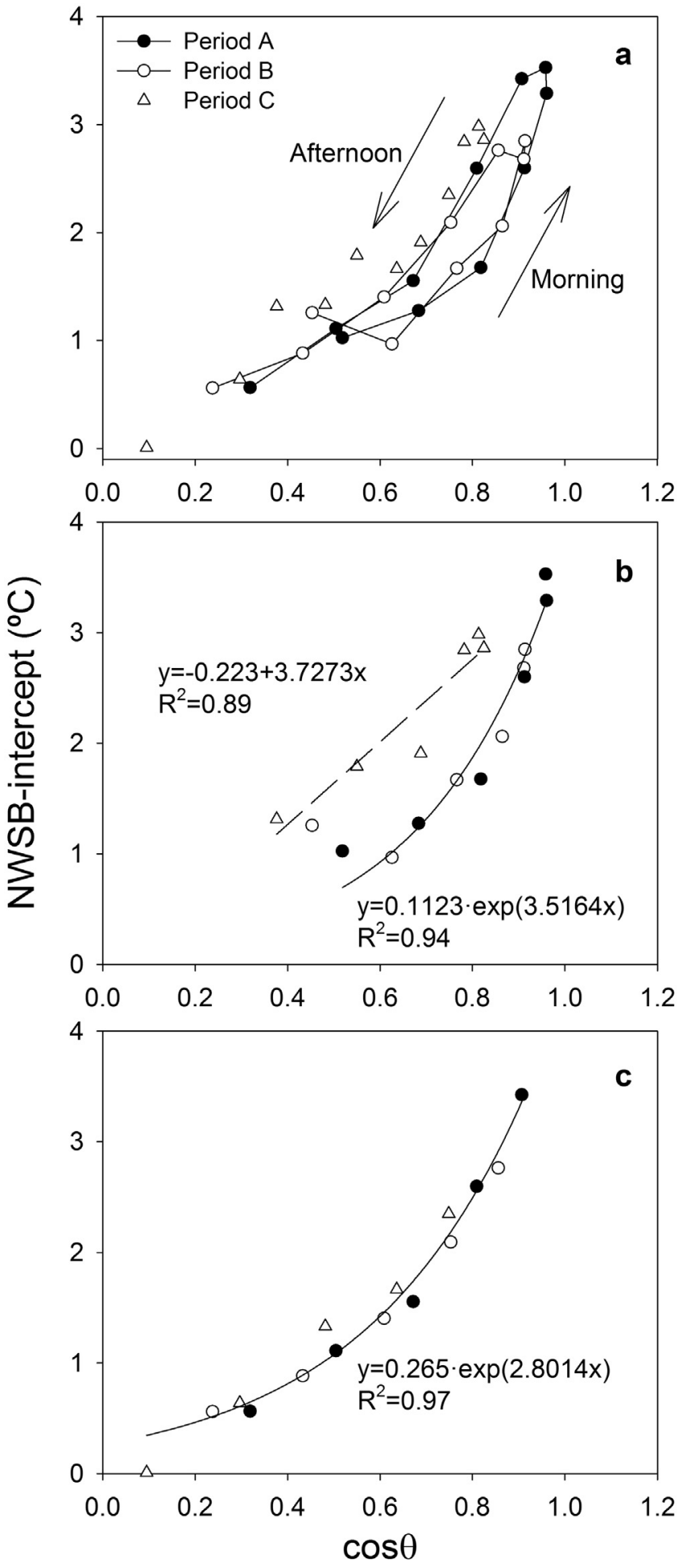

Fig. 8. Relationship between NWSB-intercepts and zenith solar angle for the period (a) 08:00-18:00, (b) 08:00-13:00 and (c) 13:00-18:00.

pronounced as the season progressed was observed between 8:00 to $12: 00$ GMT

Compared to other crop species, the NWSB-intercept derived for olives (the maximum was approximately $3.5^{\circ} \mathrm{C}$ for period $\mathrm{A}$ and close to $3{ }^{\circ} \mathrm{C}$ in periods B and C; Fig. 6) was within the order of magnitude of those found in the literature for other herbaceous (Idso, 1982) and woody crop species (Bellvert et al., 2015; Testi et al., 2008). However, the NWSB-slope (maximum values
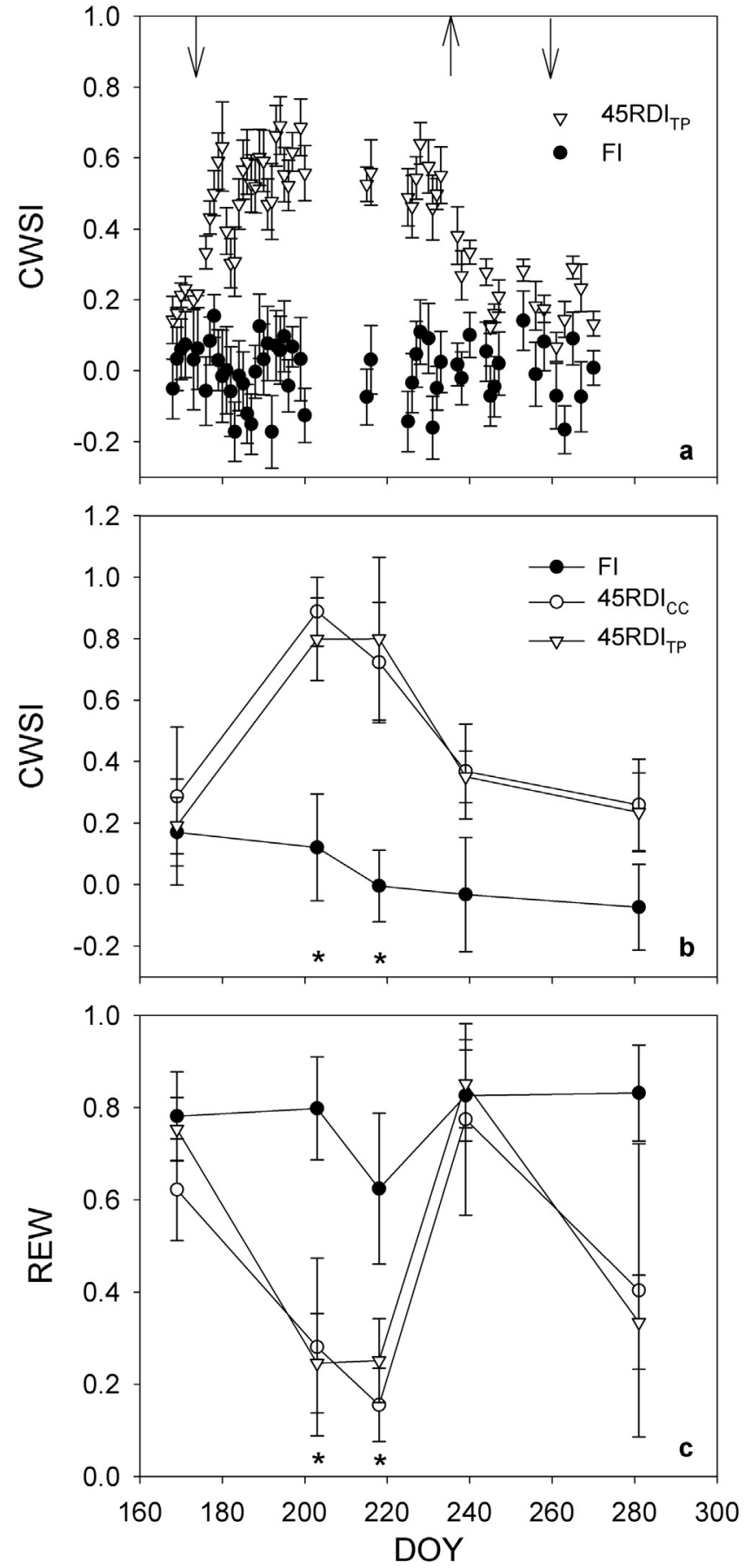

Fig. 9. Seasonal time-course of (a)CWSI determined from canopy temperature measured with the infrared thermometers (IRTS) at 12.00 GMT, (b) CWSI derived from RPAS thermal imaging (12.00 GMT) and (c) REW. The NWSB shown in Table 3 for periods $\mathrm{A}, \mathrm{B} \& \mathrm{C}$ were used in CWSI calculation. In (a), only clear-sky days were used for CWSI determination. Each point is the mean of two (a), four (b) and three (c) replicates per treatment. Down-facing arrows indicate the onset of water stress periods in RDI treatments; the up-facing arrow indicates the end of a water stress period. The error bars represent the standard error of the mean (SE). In (b) and (c), asterisks denote significant differences at $P<0.05$.

around $-0.5^{\circ} \mathrm{C} \mathrm{kPa}^{-1}$ for periods $\mathrm{A}$ and $\mathrm{B}$ and close to $-0.7^{\circ} \mathrm{C} \mathrm{kPa}^{-1}$ in period C; Fig. 7) derived for olives was substantially lower (expressed as an absolute value) than the slopes derived for other crop species, with the sole exception of the values derived for citrus trees (Gonzalez-Dugo et al., 2014). In herbaceous crops, Idso (1982) found NWSB-slope values within the interval $-3.25^{\circ} \mathrm{C} \mathrm{kPa}^{-1}$ 

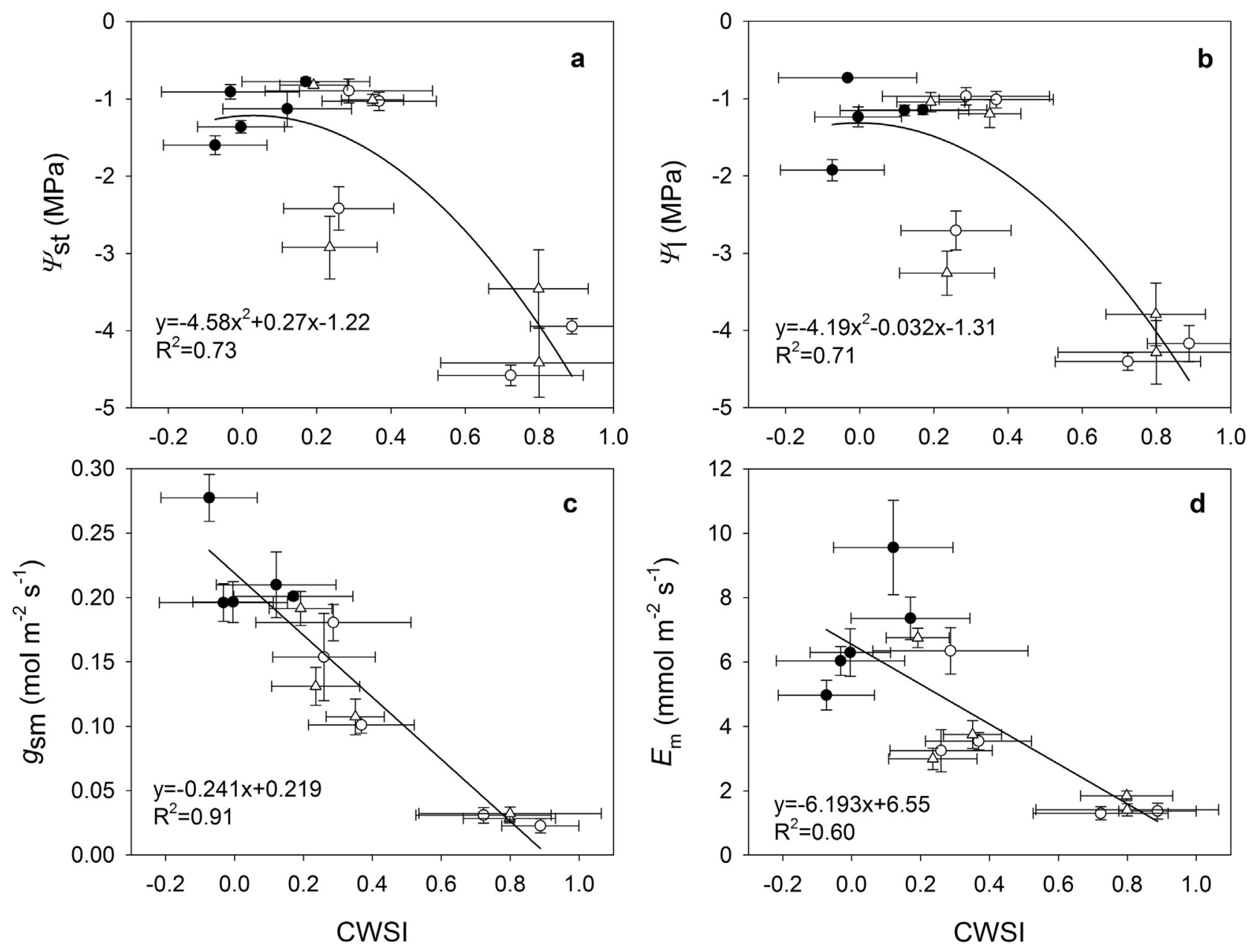

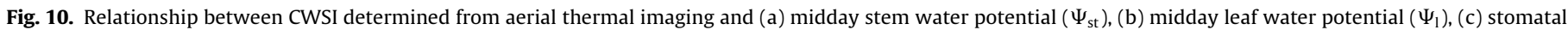
conductance $\left(g_{\mathrm{sm}}\right)$ and $(\mathrm{d})$ leaf transpiration rate $\left(E_{\mathrm{m}}\right)$ for $\mathrm{FI}, 45 \mathrm{RDI}_{\mathrm{CC}}$ and $45 \mathrm{RDI}_{\mathrm{TP}}$ treatments. The straight lines represent the fitted regression lines to the data.

to $-1.23^{\circ} \mathrm{C} \mathrm{kPa}^{-1}$, whereas in other fruit tree species the corresponding midday values were around $-1.35^{\circ} \mathrm{C} \mathrm{kPa}^{-1}$ (pistachio), $-1.7^{\circ} \mathrm{C} \mathrm{kPa}^{-1}$ (peach) and $-1.9^{\circ} \mathrm{C} \mathrm{kPa}^{-1}$ (vineyard) (Bellvert et al., 2016a, 2014; Testi et al., 2008). In olive trees, two previous studies provide controversial NWSB-slope values, as denoted by the very small slope $\left(-0.35^{\circ} \mathrm{C} \mathrm{kPa}^{-1}\right)$ obtained by Berni et al. (2009) compared to that $\left(-2.05^{\circ} \mathrm{C} \mathrm{kPa}^{-1}\right)$ reported by Bellvert et al. (2016a). Our findings are in agreement with the small slope value found by Berni et al. (2009), who argued that this value was a consequence of the small size of olive leaves, which makes them to be highly coupled to the atmosphere, causing a marked stomatal closure when the evaporative demand increases, even in trees under non-limiting soil water conditions (Fernández et al., 1997).

Seasonal differences in the NWSBs were already reported early in the 1980s for two herbaceous crops, wheat and barley (Idso, 1982), but little is known about the seasonal stability of the NWSBs derived for many others herbaceous and woody crop species. In peach trees, within season differences in the NWSB were small (Bellvert et al., 2016a); thus, a unique NWSB for the whole growing season was recommended by the authors. In olive trees, Berni et al. (2009) obtained their NWSB $\left(T_{\mathrm{c}}-T_{\mathrm{a}}=-0.35 \cdot \mathrm{VPD}+2.08, \mathrm{R}^{2}=0.67\right)$ by computing the values from clear days (12:30 GMT) from April to September. They did not report any seasonal effect on such a relationship, but stressed the high scatter and the low slope as compared to those reported by other authors. By comparing their NWSB with the one obtained in this study $\left(T_{\mathrm{c}}-T_{\mathrm{a}}=-0.36 \cdot \mathrm{VPD}+2.50\right.$, $\left.R^{2}=0.49\right)$ for the period June-September at a similar time $(12: 00$
GMT, Table 2), it can be observed that there are no differences in the slopes and the intercepts are very similar. Therefore, a plausible explanation for the high scatter reported by Berni et al. (2009) is a within-season shift in the NWSB, like the one shown by our results. Recently, Bellvert et al. (2015) found that some vineyard cultivars exhibited seasonal NWSB shifts, which were associated to variations in the energy balance of the canopy, zenith solar angle or leaf orientation. In our case study, the seasonal shift of the NWSBs (Figs. 6 and 7) was partly explained by variations in zenith solar angle (Fig. 8). In fact, the seasonal variation of NWSB-intercept derived for afternoon hours could be explained by zenith solar angle variations (Fig. 8c). However, this could not be done for the morning NWSB-intercept values, since NWSB-intercept of period C was higher than that of periods A and B for similar solar angles (Fig. 8b). In any case, the robustness of the derived NWSB to be used for irrigation scheduling, as well as its daily and seasonal dynamics, should be assessed in different locations and cultivars similarly to what has been performed for other olive water status indicators (Corell et al., 2016).

Although the CWSI values calculated from IRTs and RPAS are not fully comparable, since the former was calculated from measurements collected at one out of the four plots used to compute CWSI from RPAS measurements, both indicators followed the same seasonal trend and depicted values within the same order of magnitude, both for the FI and $45 \mathrm{RDI}_{\mathrm{TP}}$ treatments (Fig. 9). Although CWSI is supposed to vary within 0 and 1 , slightly negative values of CWSI may also be found in well-watered plants, as in our FI trees 
(Fig. 9a, b), due to the data scatter of the NWSBs (Bellvert et al., 2015; Testi et al., 2008). Values of CWSI derived from the FI trees with both sensing platforms throughout the irrigation season were close to zero. The deficit treatment that was monitored with IRTs and RPAS exhibited the highest values during the first water stress period depicted in Fig. 9 (end of June-end of August), reaching ca. 0.7 and 0.8 respectively for REW values ca. 0.2 (Fig. 9c). The close matching in CWSI trends among proximal (IRTs) and remote (RPAS) thermal sensing indicates that the $T_{\mathrm{C}}$ measurements derived from the mini RPAS using a segmentation method based on a bi-modal histogram analysis and the FWEM rule are suitable for monitoring the CWSI in SHD olive orchards.

The suitability of CWSI as a water stress index for SHD olive orchards was also demonstrated through the sound relationships found between CWSI and the reference plant water stress indicators, such as $\Psi_{\mathrm{st}}, \Psi_{1}, g_{\mathrm{sm}}$ and $E_{\mathrm{m}}$ (Fig. 10). Interestingly, the CWSI explained $91 \%$ of the variability observed in $g_{\text {sm }}$ across treatments and periods (Fig. 10c), whereas the variability of $\Psi_{\mathrm{st}}, \Psi_{1}$ and $E_{\mathrm{m}}$ that could be explained with CWSI was only 60\%-73\% (Fig. 10a, b and d). These results are in agreement with the theoretical basis of CWSI (Maes and Steppe, 2012) which denotes that, under water stress, variations in CWSI are driven by variations in $T_{\mathrm{c}}$ and $g_{\mathrm{sm}}$ is a main driving physiological variable. However, and due to the nearisohydric behavior of the olive tree (Cuevas et al., 2010), decreases in leaf and stem water potential under conditions of water stress are minimized by stomatal regulation, thus explaining the poorer relationships found between CWSI and these variables. In a previous work conducted in an olive orchard with less tree density than ours, Berni et al. (2009) also found that CWSI was linearly related to both $g_{\mathrm{sm}}$ and $\Psi_{1}$ and that CWSI was better correlated with $g_{s m}$ than with $\Psi_{1}$. However, $g_{s m}$ is not always better correlated with CWSI than $\Psi_{1}$, as recently found in nectarines (Bellvert et al., 2016a). Despite that leaf transpiration $\left(E_{\mathrm{m}}\right)$ and $g_{\mathrm{sm}}$ are strongly related (Jones, 1992), the relationship between CWSI and $E_{\mathrm{m}}$ was weaker than that with $g_{\mathrm{sm}}$ (Fig. 10), likely because $E_{\mathrm{m}}$ depends not only on $g_{\text {sm }}$ but also on the boundary layer conductance $\left(g_{\mathrm{b}}\right)$ (Jones, 1992), whose value within the leaf cuvette of the gas analyzer set by the user may greatly differ from the prevailing $g_{b}$ values in the orchard.

In the majority of studies performed to assess CWSI performance on fruit tree species, the variable used to validate the suitability of CWSI as a water status indicator was $\Psi_{\text {st }}$ (Gonzalez-Dugo et al., 2014, 2013; Testi et al., 2008) or $\Psi_{1}$ (Bellvert et al., 2016a, 2015, 2014). However, reported relationships between CWSI and these variables are not always linear, as it has also been observed in this study (Figs. 10a, b). For mandarin and orange trees, for instance, curvilinear relationships have been reported (Gonzalez-Dugo et al., 2014). In other species, such as grapevine (Bellvert et al., 2015,2014) or peach (Bellvert et al., 2016a; Gonzalez-Dugo et al., 2013) both linear and curvilinear relationships have been reported.

\section{Conclusions}

The Non-Water-Stressed Baseline (NWSB) for CWSI calculation in SHD olive orchards was not constant throughout the growing season, but its seasonal shift could be partly explained by variations in zenith solar angle. Both NWSB-intercepts and NWSB-slopes exhibited diurnal variation, but these trends were successfully modeled with polynomial equations to ease CWSI calculation at any time of the day. In order to reduce the empiricism and site specificity of these models, a sound relationship between NWSBintercept and solar angle was found. The CWSI values derived from high-resolution thermal imagery captured from a mini RPAS demonstrated to be a suitable indicator for both monitoring water stress and assessing water status variability in SHD olive orchards.
Stomatal conductance had the tightest relationship with CWSI, over performing other widely used plant water status indicators such as leaf or stem water potential.

\section{Acknowledgments}

This work was funded by the Spanish Ministry of Economy and Competitiveness (research project AGL2012-34544, predoctoral contract grant BES-2013-065380) and by the Junta de Andalucía (research project P12-AGR-1227). Authors are grateful to Antonio Montero for his valuable contribution in the field work and to Pablo Agüera, the RPAS pilot. Thanks are also due to the owners of Internacional Olivarera, S.A. (Interoliva), for allowing us to conduct the experiments in the Sanabria farm.

\section{References}

Agam, N., Cohen, Y., Berni, J.A.J., Alchanatis, V., Kool, D., Dag, A., Yermiyahu, U., Ben-Gal, A., 2013. An insight to the performance of crop water stress index for olive trees. Agric. Water Manag. 118, 79-86, http://dx.doi.org/10.1016/j.agwat. 2012.12.004.

Agam, N., Segal, E., Peeters, A., Levi, A., Dag, A., Yermiyahu, U., Ben-Gal, A., 2014. Spatial distribution of water status in irrigated olive orchards by thermal imaging. Precis. Agric. 15, 346-359, http://dx.doi.org/10.1007/s11119-0139331-8.

Alderfasi, A.A., Nielsen, D.C., 2001. Use of crop water stress index for monitoring water status and scheduling irrigation in wheat. Agric. Water Manag. 47, 69-75.

Bellvert, J., Zarco-Tejada, P.J., Girona, J., Fereres, E., 2014. Mapping crop water stress index in a Pinot-noir vineyard: comparing ground measurements with therma remote sensing imagery from an unmanned aerial vehicle. Precis. Agric. 15, 361-376, http://dx.doi.org/10.1007/s11119-013-9334-5.

Bellvert, J., Marsal, J., Girona, J., Zarco-Tejada, P.J., 2015. Seasonal evolution of crop water stress index in grapevine varieties determined with high-resolution remote sensing thermal imagery. Irrig. Sci. 33, 81-93, http://dx.doi.org/10. 1007/s00271-014-0456-y.

Bellvert, J., Marsal, J., Girona, J., Gonzalez-Dugo, V., Fereres, E., Ustin, S.L. Zarco-Tejada, P.J., 2016a. Airborne thermal imagery to detect the seasonal evolution of crop water status in peach, nectarine and Saturn peach orchards. Remote Sens. 8, 1-17, http://dx.doi.org/10.3390/rs8010039.

Bellvert, J., Zarco-Tejada, P.J., Marsal, J., Girona, J., González-Dugo, V., Fereres, E., 2016b. Vineyard irrigation scheduling based on airborne thermal imagery and water potential thresholds. Aust. J. Grape Wine Res. 22, 307-315, http://dx.doi. org/10.1111/ajgw.12173.

Ben-Gal, A., Agam, N., Alchanatis, V., Cohen, Y., Yermiyahu, U., Zipori, I., Presnov, E. Sprintsin, M., Dag, A., 2009. Evaluating water stress in irrigated olives: correlation of soil water status, tree water status, and thermal imagery. Irrig. Sci. 27, 367-376, http://dx.doi.org/10.1007/s00271-009-0150-7.

Berni, J.A.J., Zarco-Tejada, P.J., Sepulcre-Cantó, G., Fereres, E., Villalobos, F., 2009. Mapping canopy conductance and CWSI in olive orchards using high resolution thermal remote sensing imagery. Remote Sens. Environ. 113, 2380-2388, http://dx.doi.org/10.1016/j.rse.2009.06.018.

Corell, M., Pérez-López, D., Martín-Palomo, M.J., Centeno, A., Girón, I., Galindo, A., Moreno, M.M., Moreno, C., Memmi, H., Torrecillas, A., Moreno, F., Moriana, A. 2016. Comparison of the water potential baseline in different locations. Usefulness for irrigation scheduling of olive orchards. Agric. Water Manag. 177 308-316, http://dx.doi.org/10.1016/j.agwat.2016.08.017.

Couvreur, V., Kandelous, M.M., Sanden, B.L., Lampinen, B.D., Hopmans, J.W., 2016. Downscaling transpiration rate from field to tree scale. Agric. For. Meteorol. 221, 71-77, http://dx.doi.org/10.1016/j.agrformet.2016.02.008.

Cuevas, M.V., Torres-Ruiz, J.M., Âlvarez, R., Jiménez, M.D., Cuerva, J., Fernández, J.E. 2010. Assessment of trunk diameter variation derived indices as water stress indicators in mature olive trees. Agric. Water Manag. 97, 1293-1302, http://dx. doi.org/10.1016/j.agwat.2010.03.011.

Cuevas, M.V., Martín-Palomo, M.J., Diaz-Espejo, A., Torres-Ruiz, J.M., Rodriguez-Dominguez, C.M., Perez-Martin, A., Pino-Mejías, R., Fernández, J.E., 2013. Assessing water stress in a hedgerow olive orchard from sap flow and trunk diameter measurements. Irrig. Sci. 31, 729-746, http://dx.doi.org/10. 1007/s00271-012-0357-x.

Dupin, S., Gobrecht, A., Tisseyre, B., 2011. Airborne thermography of vines canopy: effect of the atmosphere and mixed pixels on observed canopy temperature. 8 ème Conférence Eur. sur l'Agriculture Précision, 1-9.

Egea, G., Diaz-Espejo, A., Fernández, J.E., 2016. Soil moisture dynamics in a hedgerow olive orchard under well-watered and deficit irrigation regimes: assessment, prediction and scenario analysis. Agric. Water Manag. 164, 197-211, http://dx.doi.org/10.1016/j.agwat.2015.10.034.

Fernández, J.E., Moreno, F., Girón, I.F., Blázquez, O.M., 1997. Stomatal control of water use in olive tree leaves. Plant Soil 190, 179-192, http://dx.doi.org/10. 1023/A:1004293026973.

Fernández, J.E., Moreno, F., Martín-Palomo, M.J., Cuevas, M.V., Torres-Ruiz, J.M., Moriana, A., 2011. Combining sap flow and trunk diameter measurements to 
assess water needs in mature olive orchards. Environ. Exp. Bot. 72, 330-338, http://dx.doi.org/10.1016/j.envexpbot.2011.04.004.

Fernández, J.E., Perez-Martin, A., Torres-Ruiz, J.M., Cuevas, M.V.,

Rodriguez-Dominguez, C.M., Elsayed-Farag, S., Morales-Sillero, A., García, J.M. Hernandez-Santana, V., Diaz-Espejo, A., 2013. A regulated deficit irrigation strategy for hedgerow olive orchards with high plant density. Plant Soil 372, 279-295, http://dx.doi.org/10.1007/s11104-013-1704-2.

Fernández, J.E., 2014. Understanding olive adaptation to abiotic stresses as a tool to increase crop performance. Environ. Exp. Bot. 103, 158-179, http://dx.doi.org/ 10.1016/j.envexpbot.2013.12.003.

Fuchs, M., Tanner, C.B., 1966. Infrared thermometry of vegetation1. Agron. J. 58, 597, http://dx.doi.org/10.2134/agronj1966.00021962005800060014x.

Gómez Del Campo, M., García, J.M., 2013. Summer deficit-irrigation strategies in a hedgerow olive cv. arbequina orchard: effect on oil quality. J. Agric. Food Chem. 61, 8899-8905, http://dx.doi.org/10.1021/jf402107t.

Gonzalez-Dugo, V., Zarco-Tejada, P., Nicolás, E., Nortes, P.A., Alarcón, J.J., Intrigliolo, D.S., Fereres, E., 2013. Using high resolution UAV thermal imagery to assess the variability in the water status of five fruit tree species within a commercial orchard. Precis. Agric. 14, 660-678, http://dx.doi.org/10.1007/s11119-0139322-9.

Gonzalez-Dugo, V., Zarco-Tejada, P.J., Fereres, E., 2014. Applicability and limitations of using the crop water stress index as an indicator of water deficits in citrus orchards. Agric. For. Meteorol. 198 (-199), 94-104, http://dx.doi.org/ 10.1016/j.agrformet.2014.08.003.

Hatfield, J.L., Wanjura, D.F., Barker, G.L, 1985. Canopy temperature response to water stress under partial canopy. Trans. Am. Soc. Agric. Eng. 28, 1607-1611.

Idso, S.B., Jackson, R.D., Pinter, P.J., Reginato, R.J., Hatfield, J.L., 1981. Normalizing the stress-degree-day parameter for environmental variability. Agric. Meteorol. 24, 45-55, http://dx.doi.org/10.1016/0002-1571(81)90032-7.

Idso, S.B., 1982. Non-water-stressed baselines: a key to measuring and interpreting plant water stress. Agric. Meteorol. 27, 59-70.

Irmak, S., Haman, D.Z., Bastug, R., 2000. Determination of crop water stress index for irrigation timing and yield estimation of corn. Agron. J. 92, 1221, http://dx. doi.org/10.2134/agronj2000.9261221x.

Jackson, R.D., Idso, S.B., Reginato, R.J., Pinter, P.J., 1981. Canopy temperature as a crop water stress indicator. Water Resour. Res. 17, 1133-1138, http://dx.doi. org/10.1029/WR017i004p01133.

Jiménez-Bello, M.A., Ballester, C., Castel, J.R., Intrigliolo, D.S., 2011. Development and validation of an automatic thermal imaging process for assessing plant water status. Agric. Water Manag. 98, 1497-1504, http://dx.doi.org/10.1016/j. agwat.2011.05.002.

Jones, H.G., 1992. Plants and Microclimate: A Quantitative Approach to Environmental Plant Physiology. Cambridge University Press.

Jones, H.G., 2007. Monitoring plant and soil water status: established and novel methods revisited and their relevance to studies of drought tolerance. J. Exp. Bot. 58, 119-130, http://dx.doi.org/10.1093/jxb/erl118.
Möller, M., Alchanatis, V., Cohen, Y., Meron, M., Tsipris, J., Naor, A., Ostrovsky, V., Sprintsin, M., Cohen, S., 2007. Use of thermal and visible imagery for estimating crop water status of irrigated grapevine. J. Exp. Bot. 58, 827-838, http://dx.doi.org/10.1093/jxb/erl115.

Maes, W.H., Steppe, K., 2012. Estimating evapotranspiration and drought stress with ground-based thermal remote sensing in agriculture: a review. Jorunal Exp. Bot. 63, 4671-4712, http://dx.doi.org/10.1093/jxb/ers165.

Nielsen, D.C., Anderson, R.L., 1989. Infrared thermometry to measure single leaf temperatures for quantification of water-stress in sunflowe. Agron. J. 81, 840-842.

Padilla-Díaz, C.M., Rodriguez-Dominguez, C.M., Hernandez-Santana, V., Perez-Martin, A., Fernández, J.E., 2016. Scheduling regulated deficit irrigation in a hedgerow olive orchard from leaf turgor pressure related measurements. Agric. Water Manag. 164, 28-37, http://dx.doi.org/10.1016/j.agwat.2015.08. 002.

R Core Team, 2015. R: A Language and Environment for Statistical Computing. R Foundation for Statistical Computing, Vienna, Austria.

Rius, X., Lacarte, J.M., 2010. La Revolución Del Olivar. El Cultivo En Seto. Locator Maps PTY. LTD.

Rud, R., Cohen, Y., Alchanatis, V., Beiersdorf, I., Klose, R., Presnov, E., Levi, A. Brikman, R., Agam, N., Dag, A., Ben-Gal, A., 2015. Characterization of salinity-induced effects in olive trees based on thermal imagery. In: Precis. Agric. 2015 - Pap. Present. 10th Eur. Conf. Precis. Agric., ECPA 2015, pp. 511-517.

Scholander, P.F., Hammel, H.T., Bradstreet, E.D., Hemmingsen, E.A., 1965. Sap Pressure in Vascular Plants: negative hydrostatic pressure can be measured in plants. Science 148, 339-346, http://dx.doi.org/10.1126/science.148.3668.339 (80-.).

Sepulcre-Cantó, G., Zarco-Tejada, P.J., Jiménez-Muñoz, J.C., Sobrino, J.A., De Miguel, E., Villalobos, F.J., 2006. Detection of water stress in an olive orchard with thermal remote sensing imagery. Agric. For. Meteorol. 136, 31-44, http://dx. doi.org/10.1016/j.agrformet.2006.01.008.

Testi, L., Goldhamer, D.A., Iniesta, F., Salinas, M., 2008. Crop water stress index is a sensitive water stress indicator in pistachio trees. Irrig. Sci. 26, 395-405, http:// dx.doi.org/10.1007/s00271-008-0104-5.

Xie, Y., Sha, Z., Yu, M., 2008. Remote sensing imagery in vegetation mapping: a review. J. Plant Ecol. 1, 9-23, http://dx.doi.org/10.1093/jpe/rtm005.

Zimmermann, D., Reuss, R., Westhoff, M., Gessner, P., Bauer, W., Bamberg, E. Bentrup, F.-W., Zimmermann, U., 2008. A novel, non-invasive, online-monitoring, versatile and easy plant-based probe for measuring leaf water status. J. Exp. Bot. 59, 3157-3167, http://dx.doi.org/10.1093/jxb/ern171. 